\title{
November 2003 event: effects on the Earth's ionosphere observed from ground-based ionosonde and GPS data
}

\author{
E. Blanch ${ }^{1}$, D. Altadill ${ }^{1}$, J. Boška ${ }^{2}$, D. Burešová ${ }^{2}$, and M. Hernández-Pajares ${ }^{3}$ \\ ${ }^{1}$ Observatori de l'Ebre, URL - CSIC, Roquetes, Spain \\ ${ }^{2}$ Institute of Atmospheric Physics, Academy of Sciences CR, Prague, Czech Republic \\ ${ }^{3}$ Technical University of Catalonia, UPC/gAGE, Barcelona, Spain
}

Received: 9 February 2005 - Revised: 2 September 2005 - Accepted: 22 September 2005 - Published: 22 November 2005

Part of Special Issue "1st European Space Weather Week (ESWW)"

\begin{abstract}
Intense late-cycle solar activity during October and November 2003 produced two strong geomagnetic storms: 28 October-5 November 2003 (October) and 1923 November 2003 (November); both reached intense geomagnetic activity levels, $K_{p}=9$, and $K_{p}=8+$, respectively. The October 2003 geomagnetic storm was stronger, but the effects on the Earth's ionosphere in the mid-latitude European sector were more important during the November 2003 storm. The aim of this paper is to discuss two significant effects observed on the ionosphere over the mid-latitude European sector produced by the November 2003 geomagnetic storm, using data from ground ionosonde at Chilton $\left(51.5^{\circ} \mathrm{N}\right.$; $\left.359.4^{\circ} \mathrm{E}\right)$, Pruhonice $\left(50.0^{\circ} \mathrm{N} ; 14.6^{\circ} \mathrm{E}\right)$ and El Arenosillo $\left(37.1^{\circ} \mathrm{N} ; 353.3^{\circ} \mathrm{E}\right)$, jointly with GPS data. These effects are the presence of well developed anomalous storm $E_{S}$ layers observed at latitudes as low as $37^{\circ} \mathrm{N}$ and the presence of two thin belts: one having enhanced electron content and other, depressed electron content. Both reside over the mid-latitude European evening sector.
\end{abstract}

Keywords. Ionosphere (Mid-latitude ionosphere; Ionospheric Disturbances; Particle Precipitation)

\section{Introduction}

A geomagnetic storm is the most important space weather phenomenon from the point of view of the impact on the global magnetosphere-ionosphere-thermosphere system. The storm is supplied by solar wind energy, captured by the magnetosphere, and transformed and dissipated in the highlatitude upper atmosphere. It affects the complex morphology of the electric fields, winds, temperature and composition, and it causes changes in the state of ionospheric ion-

Correspondence to: E. Blanch

(eblanch@obsebre.es) ization. One of the main characteristics of the disturbed ionosphere is a great degree of variability. Due to many interacting factors, each storm could show a different course. During geomagnetic storms the electron density can either increase (positive ionospheric storm) or decrease (negative ionospheric storm). The electric fields, thermospheric meridional winds, a "composition bulk" and high latitude particle precipitation have been suggested as probable physical mechanisms to explain the ionospheric response to storminduced disturbances observed at different altitudes and latitudes (Fuller-Rowell et al., 1994; Prölls, 2004). Severe ionospheric disturbances originated by solar flares have significant effects on the propagation of radio waves over the entire radio spectrum, which is crucial for radio communications and navigation systems (Ondoh and Marubashi, 2001; Thomson et al., 2004). Studies of the ionospheric reaction to geomagnetic storms are of great importance and there are numerous publications on the topic (e.g. Buonsanto, 1999; Danilov, 2001; Lastovicka, 2002; Mansilla, 2004; and many others). Nevertheless, many features of this phenomenon are still not clear due to many different processes interacting in the Earth's atmospheric system.

Between 18 October and 5 November of 2003, in a descending phase 11-year solar sunspot cycle, two periods of a suddenly enhanced solar activity, primary caused by two different, large, sunspot groups, occurred. There were eleven large X-class flares during this period. On 28 October 2003, a powerful solar flare X17 erupted from giant sunspot 486 . It struck the Earth on 29 October, and was responsible for the 28 October -5 November 2003 geomagnetic storm (also known as the Halloween event). In the middle of November, all sunspots that caused intense space weather effects in October were again visible on the Earth-facing side of the Sun. In this case it was the solar flare X28 coming from sunspot 484 that was responsible for the 19-23 November 2003 geomagnetic storm. The X28 flare has been the largest one since 
Table 1. List of the ground-ionosonde stations used in this study.

\begin{tabular}{lll}
\hline Station - URSI Code & Geographic position $\left(^{\circ}\right)$ & System \\
\hline Chilton - RL052 & $51.5 \mathrm{~N}, 359.4 \mathrm{E}$ & DPS1 \\
Pruhonice - PQ052 & $50.0 \mathrm{~N} ; 14.6 \mathrm{E}$ & IPS42 \\
El Arenosillo - EA036 & $37.1 \mathrm{~N} ; 353.3 \mathrm{E}$ & DGS 256 \\
\hline
\end{tabular}

GOES began its solar measurements in 1976 (Woods et al., 2004). Large fluxes of particles were sent to the Earth from 29 to 31 October 2003, and the magnetic field component parallel to the Earth's rotation axis $\left(H_{p}\right)$ dropped to $-150 \mathrm{nT}$ twice, as recorded by the GOES-10 satellite. Moreover, the estimated planetary $K$-index $\left(K_{p}\right)$ reached severe storm levels for almost three days, the planetary $A_{p}$-index $\left(A_{p}\right)$ reached values as high as $400 \mathrm{nT}$ and the $D_{s t}$ index dropped twice below $-340 \mathrm{nT}(-349 \mathrm{nT}$ on 29 October and $-401 \mathrm{nT}$ on 30 October). Despite the high values of the Interplanetary Magnetic Field (IMF) as recorded by the Solar Wind Electron Proton Alpha Monitor instrument (SWEPAM) on the Advanced Composition Explorer (ACE), these were not unprecedented and a high magnetic field disturbance lasted only for a short time. Moreover, although the IMF proton density recorded by SWEPAM on ACE was uncertain for much of the highest solar wind speed $(1850 \mathrm{~km} / \mathrm{s})$, the relatively low proton density led to a moderate dynamic pressure. The latter, together with a short-lived negative $B_{z}$ component of the IMF, were the reasons why the October 2003 event was not unusually geoeffective, as it was expected to be. However, an even larger geomagnetic storm with $D_{s t}$ reaching $-470 \mathrm{nT}$ occurred 3 weeks later, on 20 November 2003 when the solar wind speed was only $\sim 750 \mathrm{~km} / \mathrm{s}$. Similar storms were produced by the 15 July 2000 and 31 March 2001 solar events (Skoug et al., 2004).

The aim of this paper is to show and discuss some effects observed on the ionosphere from several European ionosondes and Global Positioning System (GPS) stations during the November 2003 geomagnetic storm. A discussion of the Helio-Geophysical background for the November 2003 event is introduced. Taking into account the global extent of the great geomagnetic storms and the strong gradients involved, the simultaneously monitoring of a large ionospheric area is advantageous. The GPS data enables us to carry out electron concentration measurements along a slant signal path and to obtain Vertical Total Electron Content (VTEC) by simple mathematical formalism. The availability of ionosonde data (with high vertical resolution) and ground GPS (with high spatial and temporal resolution) brings important information for the study of the ionosphere. This is being exploited by different authors to better investigate the solar geomagnetic storms (see, for instance, Yin et al., 2004 and Liu et al., 2004, for Storm Imaging and Solar Flare studies, respectively). In the case of GPS this is also important as well, from the practical point of view, because the augmentation systems, such as EGNOS in Europe, designed for civil aviation navigation among others, can be affected (Hernandez-Pajares et al., 2005). Using both data types, ground-ionosonde and GPS, we can observe two distinct effects on the mid-latitude ionosphere over the European Sector: the generation of anomalous storm sporadic $E$ layers (similar to auroral $E_{s}$ layers), probably formed by energetic particle precipitation and with virtual heights of about 150 $200 \mathrm{~km}$ at latitudes as low as $37^{\circ} \mathrm{N}$, and the generation of two thin longitudinal belts of VTEC, one with enhanced VTEC and the other with depressed VTEC.

\section{Data}

The Helio-Geophysical background for the November 2003 event is obtained from several data sources. The IMF data are obtained from ACE MAG Level 2 data, and the Solar Wind velocity and density are obtained from ACE SWEPAM Level 2, both provided by the ACE Science Center (ASC) (http://www.srl.caltech.edu/ACE/ASC/). ACE orbits the L1 libration point, which is a point of Earth-Sun gravitational equilibrium about 1.5 million $\mathrm{km}$ from the Earth and 148.5 million $\mathrm{km}$ from the Sun. With a semi-major axis of approximately $200000 \mathrm{~km}$ the elliptical orbit affords ACE a prime view of the Sun and the galactic regions beyond. Proton fluxes and the magnetic field component parallel to the Earth's rotation axis $\left(H_{p}\right)$ at geostationary orbit distance from the Earth are obtained from GOES-10 satellite data (longitude of $135^{\circ} \mathrm{W}$ ) at the Space Environment Center (http://sec.noaa.gov/Data/). The geomagnetic activity indices $A_{p}$ and $D_{s t}$ are obtained from the International Service of Geomagnetic Indices (ISIG) of the International Association of Geomagnetism and Aeronomy (IAGA) at http://www.cetp.ipsl.fr/ isgi/homepag1.htm.

The effects on the Earth's ionosphere during the November 2003 geomagnetic storm were observed from ground-based ionosonde and GPS data. Table 1 shows the ionosonde stations involved in this study. Data from Pruhonice and El Arenosillo were supplied directly from each observatory and Chilton data were obtained via ftp from WDCC1 at RAL, ftp://wdec1.bnsc.rl.ac.uk/.

Ground-based ionosonde offers high resolution data up to the ionospheric $F$ region maximum electron density height $h_{m} F_{2}$, providing a vertical electron density profile $(N(h))$. We computed the "true height" profiles of plasma frequency $\left(f_{p}\right)$ in the altitude range from 90 to $800 \mathrm{~km}$ for Chilton and El Arenosillo ionograms. Note that $f_{p}$ is related to the electron density by the well-known expression

$N=\frac{1}{80.6} f_{p}^{2}$,

where $f_{p}$ is expressed in $H_{z}$ and $N$ in $\mathrm{m}^{-3}$.

We used the standard "true height" inversion algorithm described by Huang and Reinisch (1996) to calculate the bottomside profiles, and the Reinisch and Huang (2001) algorithm has been used to calculate the topside profiles. The electron density profiles were obtained after operatorscaled ionograms were obtained by the DGS 256 and DPS4 
sounders of El Arenosillo and Chilton, respectively, to ensure profile data quality and to avoid possible mistakes from the automatic scaling data recorded by the sounders.

To obtain good information above $h_{m} F_{2}$ (up to $20000 \mathrm{~km}$ high), we used the ground Global Positioning System data to estimate accurately VTEC, with typical errors of a few TECUs (Hernandez-Pajares et al., 1999). Using data from the 928 available GPS stations in the Northern Hemisphere, a global map with high time resolution $(10 \mathrm{~min})$ showing the VTEC evolution in the Northern Hemisphere has been computed. An ionospheric tomographic voxel model was solved by running a Kalman filter feed with data from about 150 worldwide distributed GPS receivers belonging to the International GPS Service (IGS) network (see more details in Hernandez-Pajares et al., 2002). Afterwards, to reach the maximum available resolution, the overall available GPS receiver measurements in the Northern Hemisphere (900+) were transformed to STEC by aligning the ionospheric carrier phase observable to the first tomographic determination.

\section{Background}

The Helio-Geophysical conditions raised during the 1921 November 2003 event are depicted in Fig. 1. This figure shows the solar wind (SW) background at 1.5 million $\mathrm{km}$ from the Earth (plots a, b and c). We observe that the $B_{z}$ component of the IMF displays large variability, starting at about 07:30 UT on 20 November. It dropped rapidly to strongly negative values (reaching a minimum value of about $-50 \mathrm{nT}$ ), and negative values of $B_{z}$ are long-lasting (from about 11:00 to 23:00 UT on 20 November). As first suggested by Dungey (1961), the $B_{z}$ orientation has an important influence on the magnetosphere and high-latitude ionosphere, and the more negative $B_{z}$ is, the more important are the effects on the ionosphere (Davis et al., 1997). Moreover, an abrupt increase in the SW velocity (from about 450 to $750 \mathrm{~km} / \mathrm{s}$ ) and in the SW density (by factor 3) is noticed at about 07:30 UT on 20 November. These enhancements last for about $4 \mathrm{~h}$, and afterwards, the SW velocity returns to typical values of about $500 \mathrm{~km} / \mathrm{s}$, whereas SW density displays three additional bursts, the largest one occurring from 15:00 to 21:00 UT on 20 November. These facts provide a significant enhancement of the dynamic pressure of the SW on the magnetosphere and may leave satellites unprotected, thus causing damage.

This fact is observed from GOES-10 data. Plot (d) of Fig. 1 shows how the $H_{p}$ at the GOES position dropped suddenly to $-250 \mathrm{nT}$ after a relatively stable condition. The strong negative values of $H_{p}$ last for several hours, from 16:30 to 22:00 UT on 20 November, approximately. Plot (e) of Fig. 1 shows a dramatic increase in the proton flux (by a factor of 10) at about 12:00 UT on 20 November. Almost simultaneously, severe storm levels of geomagnetic activity were recorded (plots (f) and (g) of Fig. 1). The $A_{p}$ index reached $300 \mathrm{nT}\left(K_{p}=8+\right)$ between the 3 -h intervals from 16:30 to 19:30 UT on 20 November, and the $D_{s t}$ in-

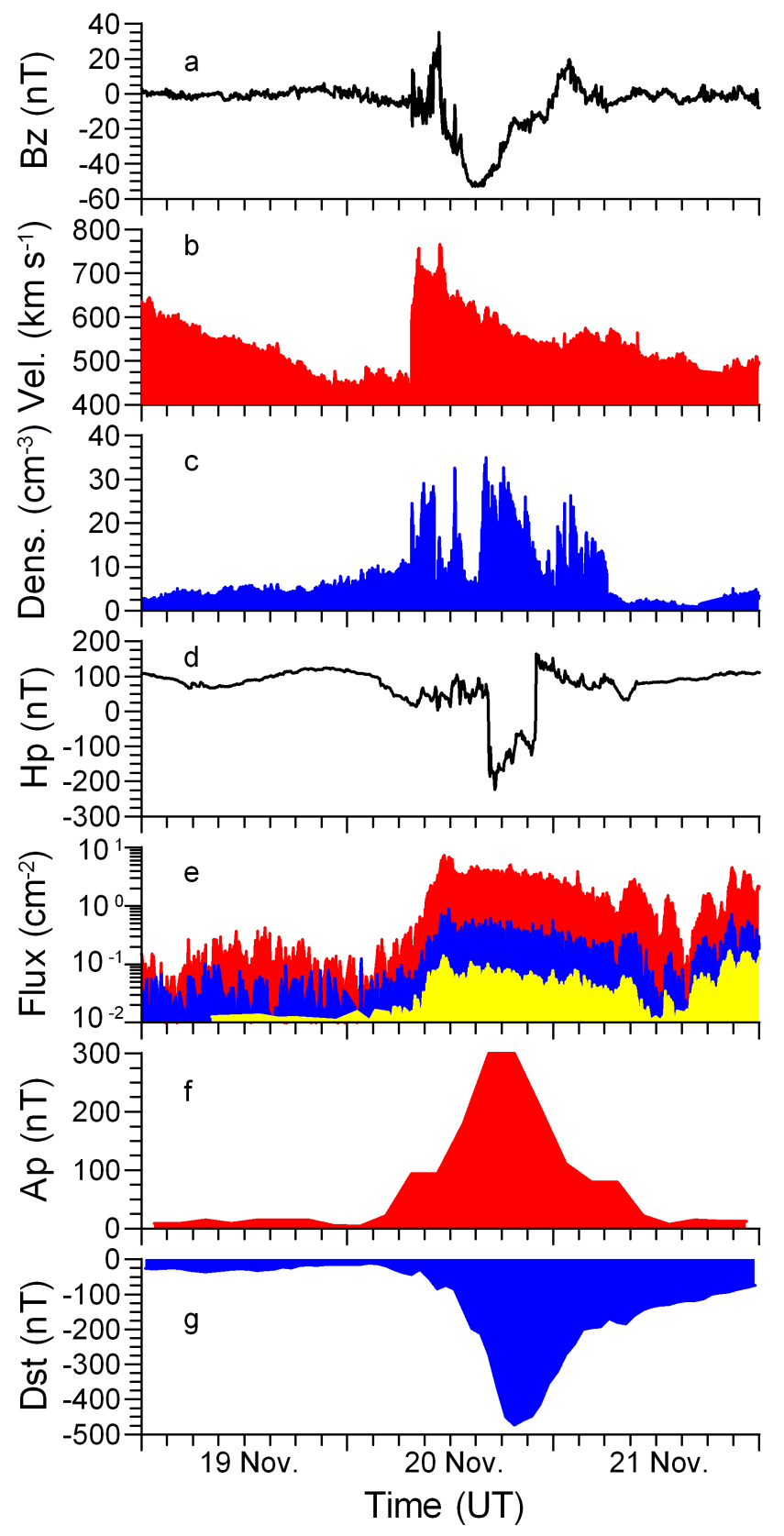

Fig. 1. Plot (a) shows the IMF $B_{z}$ component (GSM coordinate system), plot (b) shows solar wind velocity, and plot (c) shows the solar wind density; all of them recorded by the ACE satellite. Plot (d) shows the magnetic field component parallel to the Earth's rotation axis $\left(H_{p}\right)$, and plot (e) shows the proton flux (on red for proton with energy 4-9 MeV, on blue for 9-15 MeV, and on yellow for 15$40 \mathrm{MeV}$ ); all of them recorded by GOES-10. Plots (f) and (g) show the 3-h $A_{p}$ and hourly $D_{s t}$ geomagnetic activity indices, respectively (obtained from ISIG - IAGA).

dex dropped to superstorm values of about $-470 \mathrm{nT}$ at 1900 on 20 November. With the above background, strong ionospheric effects were expected. 


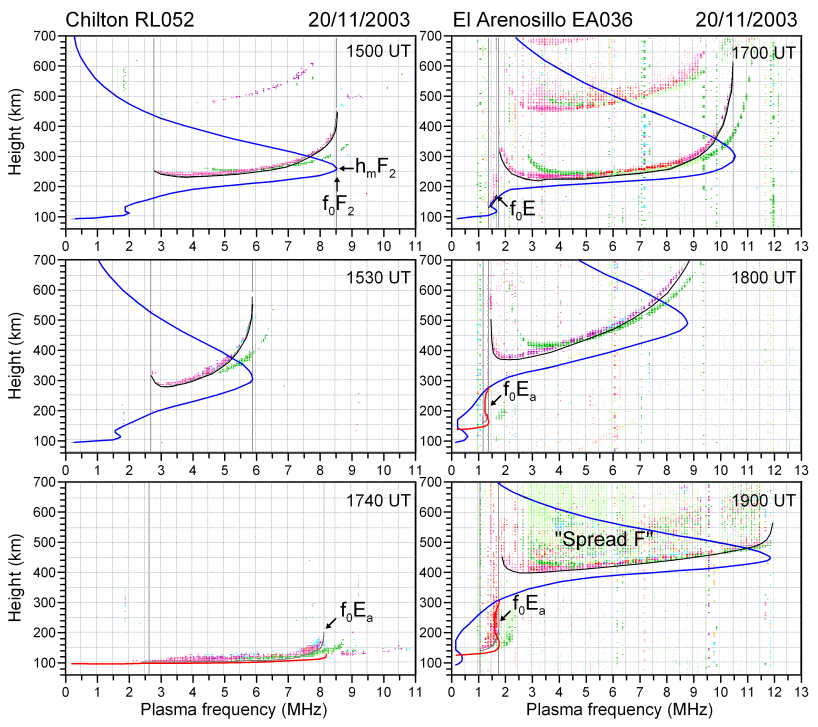

Fig. 2. Examples of ionograms obtained in Chilton (left plots) and El Arenosillo (right plots) at the indicated time. The ionograms are 2-D plots of the reflection altitude (virtual height) for a vertically emitted pulse at a given radio frequency (plasma frequency). Red to bluish dots correspond to the reflection points of the Ordinary beam and green dots correspond to the Extraordinary beam. The black lines following the trace of the Ordinary beam of the regular layers ( $E$ and $F$ ) have been used to obtain the "true height" electron density profiles (blue line) by the inversion algorithms, as described in Sect. 2. The grey lines following the Ordinary beam of the "anomalous storm $E_{S}$ " layers have been used to obtain the contribution to the electron density profiles (red line) of these anomalous layers.

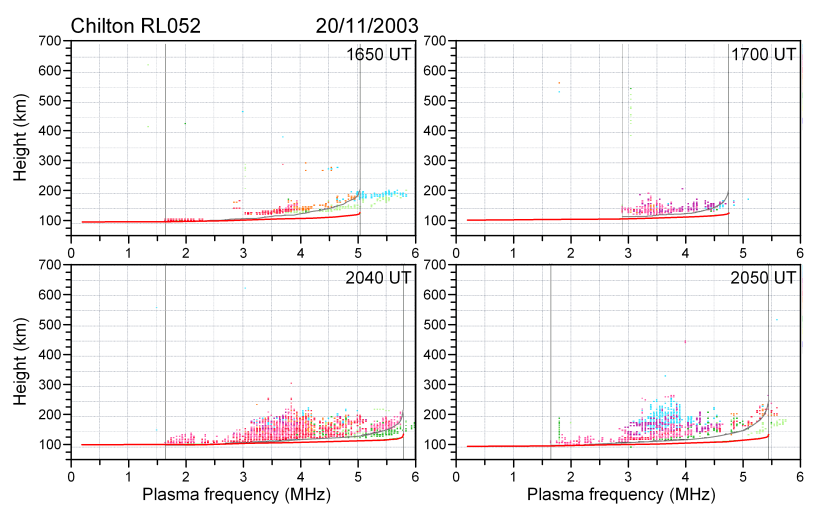

Fig. 3. Examples of ionograms recorded in Chilton at the indicated time, showing different types of "anomalous storm $E_{S}$ " layers.

\section{Observation}

The effects on the ionosphere of the strong geomagnetic storm which occurred on 20 November were observed at the three ionospheric stations listed in Table 1. Figure 2 shows some ionograms recorded at Chilton and El Arenosillo, showing distinct features of ionospheric effects caused by the 20 November event. Although not shown here, a significant increase in the electron density in the $F_{2}$ layer has been ob-

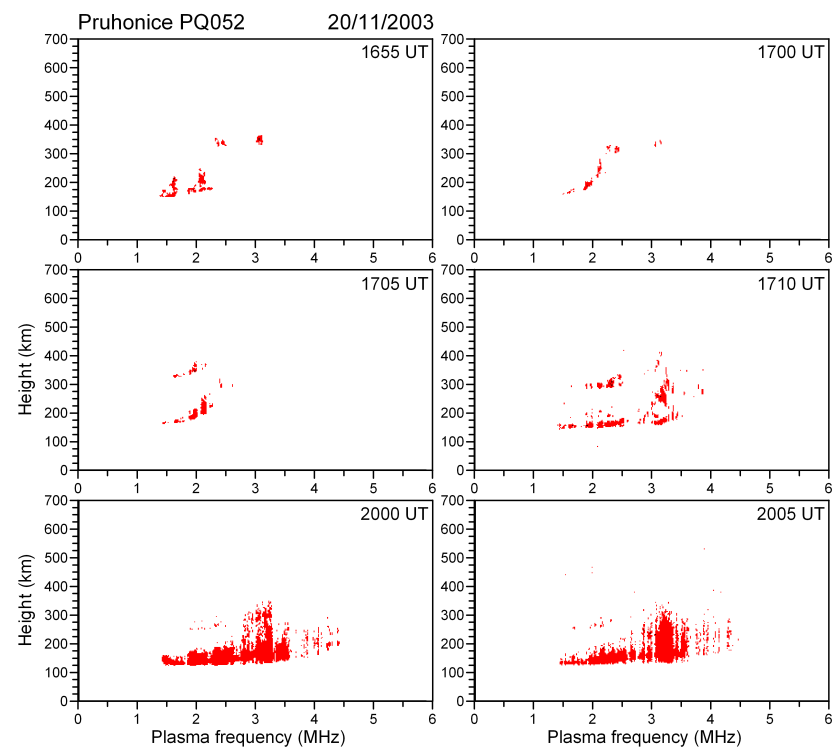

Fig. 4. As in Fig. 3, but for Pruhonice. Notice that the sounder IPS42 from Pruhonice is not able to distinguish between the ordinary and extraordinary beams in the ionograms.

served for both Chilton and Pruhonice stations at about noon, followed by a short-lasting decrease in the electron density and the later appearance of the well-developed anomalous storm $E_{s}$ layers. Above Chilton, the critical frequency of the $F_{2}$ layer, $f_{0} F_{2}$, started to become smaller and the $F_{2}$ layer electron density peak altitude, $h_{m} F_{2}$, increased rapidly after 15:00 UT. The anomalous storm $E_{s}$ layer, developed at the height of $110 \mathrm{~km}$, was first recorded on Chilton ionograms at 16:40 UT, with a corresponding density much larger than under quiet conditions. Echo patterns showed a flat, slowly rising, lower edge with a rapidly changing stratified structure. The spreading ranged over several hundred kilometres in virtual height. These anomalous storm $E_{s}$ layers were exhibited for several hours, until 22:30 UT, approximately, and it hid the $F$-region evolution (blanketing effect). The left plots of Figs. 2 and 3 show some of the ionograms representing the above facts. Quite similar ionospheric responses to storm-induced disturbances, as the ones observed above Chilton station, were observed above the Pruhonice observatory. At 16:55 UT a thick anomalous $E_{s}$ layer appeared and it lasted for several hours (Fig. 4). Comparing with Chilton, the anomalous storm $E_{s}$ layer over Pruhonice was observed at higher altitudes (from 120 to $150 \mathrm{~km}$ ) and also hid the $F$ region behaviour most of the time until midnight. A positive storm effect on the ionospheric $F$-region electron density above the El Arenosillo station was observed at about 09:00 UT (to be discussed later in Fig. 5). From 18:00 UT to 23:00 UT, El Arenosillo recorded a significant increase in $f_{0} F_{2}$ and $h_{m} F_{2}$, and a strong spread $F$ condition was clearly observed, lasting practically the whole night of 20 November. We observed that the anomalous storm $E_{s}$ layers also appeared above this mid-low latitude station, although not as strong as over the other two stations, and it did not hide the 
$F$ region on the ionograms (right ionograms in Fig. 2). This unusual sporadic $E_{S}$ layer persisted only three hours in the El Arenosillo ionograms and it was able to observe the time response of the $F$-region from the ionograms. The occurrence of this unusual storm $E_{S}$ layer is very rare at mid-latitude stations.

The thick "night-time $E$ " layers usually occur in auroral regions at times of geomagnetic disturbances, as discussed by King (1962). According to Brown and Wynne (1967), this can also be observed at mid-latitudes in association with auroral activity. The phenomenon of the anomalous storm $E_{S}$ is attributed to particle precipitation during ionospheric disturbances and to electromagnetic drift produced by the storm electric field system. The evening and night-time ionograms recorded at Chilton and Pruhonice during 20 November 2003 show the presence of such an anomalous storm $E_{s}$, and some of them remind us of the shape of the auroral $E_{s}$ layers or particle $E_{s}$ layers (Figs. 3 and 4). According to the Report UAG23A of the World Data Center A (1978), as well as its revised edition (1986), the anomalous storm $E_{S}$ layers observed in the Chilton ionograms at 16:50 and 17:00 UT (Fig. 3) and at 17:40 UT (Fig. 2) can be classified as standard type $r$ (retardation), with a slightly rising edge and spreaded trace. Therefore, it can also be interpreted that the particle layer is blanketed by the $r$ type $E_{s}$. The anomalous storm $E_{s}$ layer, which is present in the Chilton ionograms recorded after 20:00 UT, seems to be closer to the standard type $a$ (auroral) than type $r E_{s}$ layers.

The particle $E_{s}$ layer (type $k$ ) is a thick layer, which is produced by the participating particles moving into the lower atmosphere during ionospheric disturbances, showing a larger virtual height than that of the normal $E_{s}$ (up to $170 \mathrm{~km}$ ). This is often observed in the night-time with a type $r$ or type $a$ trace at high latitudes. However, the anomalous storm $E_{s}$ layers observed in the higher-middle latitude station Pruhonice ionograms, from 16:55 to 17:10 UT (Fig. 4), and in the lower-middle latitude station El Arenosillo ionograms, from 18:00 to 19:00 UT (Fig. 2), can also be classified as type $k$. The anomalous $E_{s}$ layer recorded in the later Pruhonice ionograms, starting at 20:00 UT, seems to be closer to a type $a E_{s}$, exhibited together with a $r$ type trace (Fig. 4). The occurrence of the auroral $E_{S}$ layers over middle to lower latitudes appears to be a superstorm phenomenon produced by energetic particle precipitation.

The positive and negative effects are difficult to detect using only ground-ionosonde data due to several phenomena, such as absorption and $F$-region blanketing by sporadic $E$ layers (which occurred above Chilton and Pruhonice). A detail of the latter effect may be seen in Fig. 5 for the Chilton station. However, we are able to see a positive storm effect above the El Arenosillo station. In Fig. 5 we compare the evolution of the plasma frequency as a function of time and altitude above Chilton and El Arenosillo for perturbed day 20 November 2003 with that of the previous day. It can clearly be seen from Fig. 5 that the anomalous storm $E_{s}$ layers hide the information of the $F$ region in the Chilton ionograms. This is why the contour plot of Fig. 5, correspond-

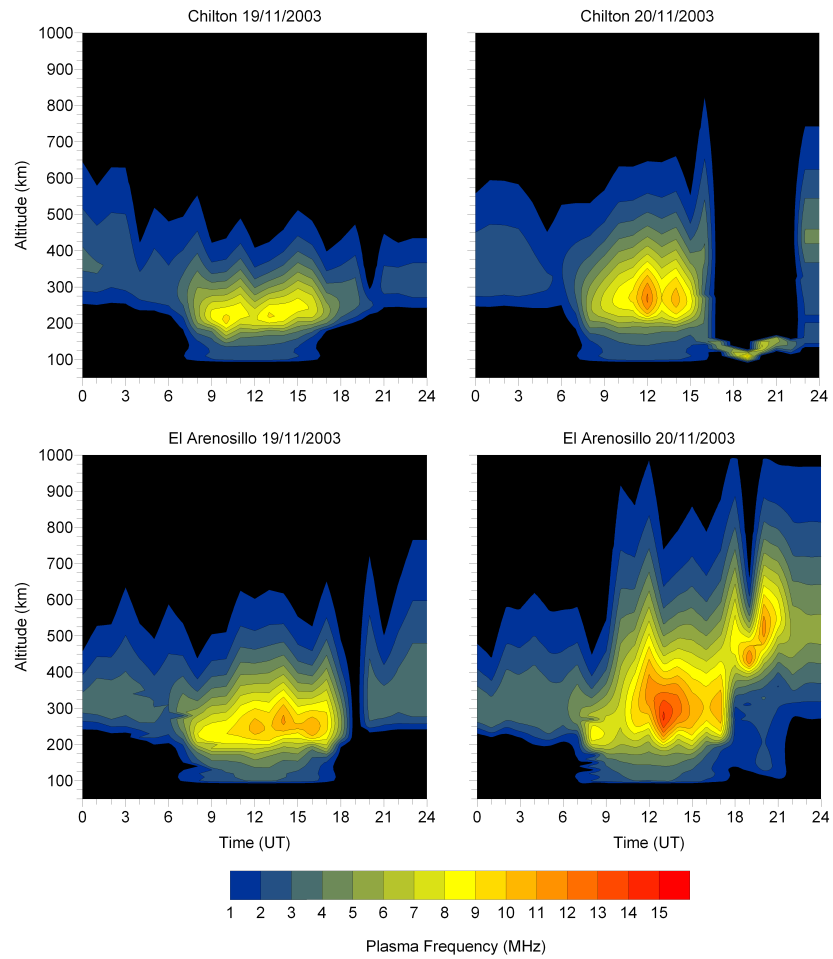

Fig. 5. Time-altitude cross-section plots of plasma frequency above Chilton (top plots) and El Arenosillo (bottom plots) on the indicated days. The colour scale at the bottom indicates the different levels of plasma frequency.

ing to Chilton for the perturbed day, only accounts for the contribution of the "anomalous storm $E_{S}$ " layers during the time interval 16:50-22:30 UT, approximately. There are no $F$-region profiles available for that time interval because of a blanketing effect of the "anomalous storm $E_{s}$ " layers, as already discussed from Fig. 2. However, direct comparison of plasma frequency evolution above El Arenosillo between pre-storm and the storm day, allows us to observe the following facts. The daily variation of 20 November behaves quite similar to that observed for the previous day, up to early afternoon, despite the larger density around midday. In the early evening, an enhancement of plasma frequency (by a factor 3 to 4 ) is clearly stated during the initial phase of the storm (from 18:00 UT onwards). Simultaneously, the $F$ region is lifted and one can see that it also spreads in altitude. This may originate from an enhancement of the equatorward meridional component of the neutral wind, as compared with the previous day and from an enhancement of the plasma temperature, both caused by the geomagnetic storm. The latter facts can explain the lifting and widening of the $F$ region and the observed electron density enhancement, as well (Danilov, 2001; Prölls, 2004).

In order to avoid all the absorption and blanketing phenomena on the ionograms and to have additional information about the ionosphere, we use GPS ground data. The UPC/gAGE computed the VTEC evolution (every $10 \mathrm{~min}$ ) to study the ionospheric effects caused by the 

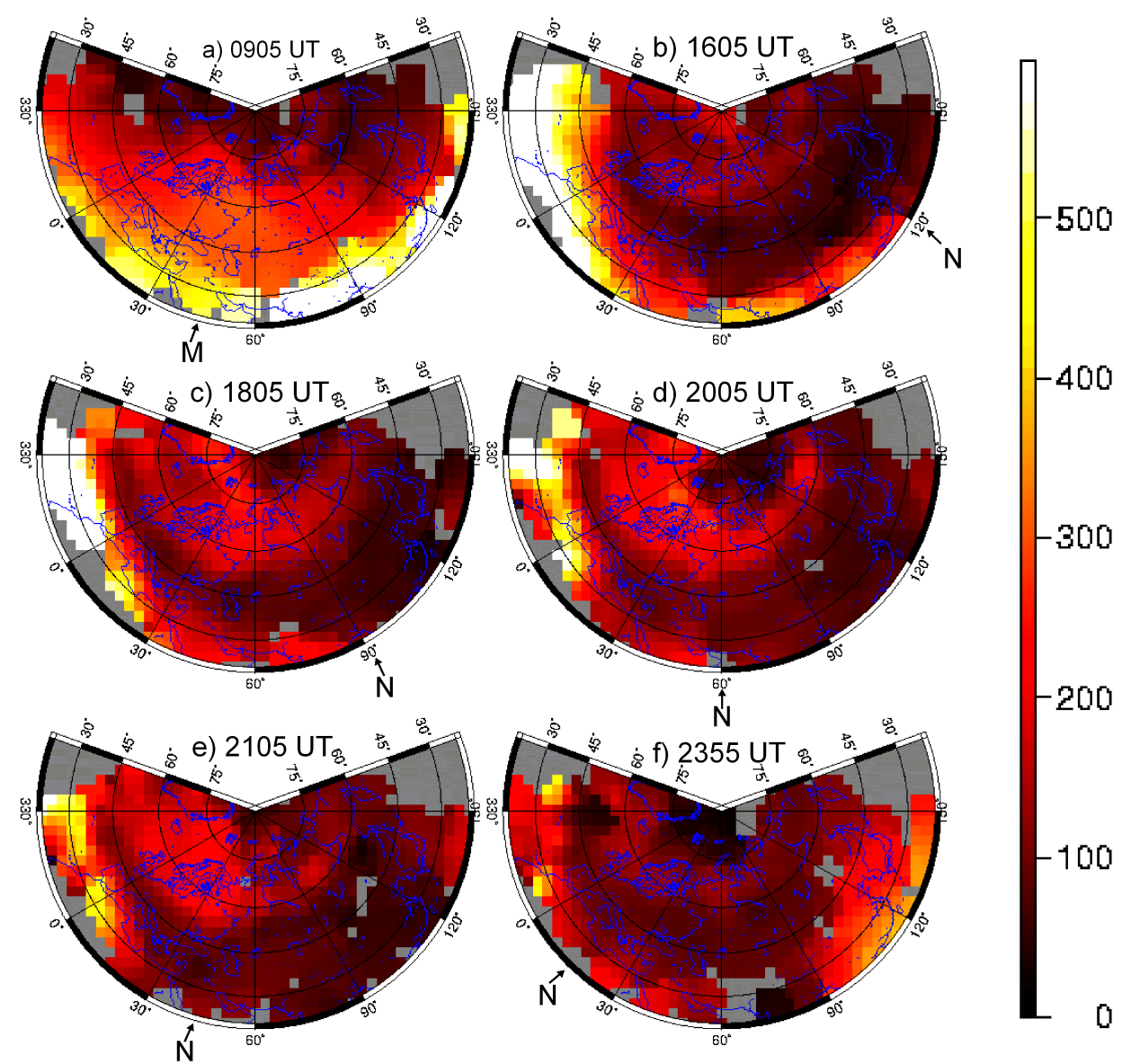

Fig. 6. Two-dimensional maps showing the evolution of VTEC on 20 November 2003 in the Euro-Asiatic Sector. The geographical parallels are plotted every 15 degrees from the geographical North Pole, and corresponding meridians plotted every 30 deg. Arrows indicate the local noon $(\mathrm{M})$ or local mid-night $(\mathrm{N})$. The color scale indicates the levels of VTEC in units of 0.1 TECU $\left(10^{15} \mathrm{~m}^{-2}\right)$. The grey regions are not covered by GPS receivers. First snapshot (a) shows the VTEC values at about the storm onset. Snapshot (b) shows VTEC at the end of the initial phase of the storm. Snapshots (c), (d), and (e) show VTEC at the main phase. Snapshot (f) shows VTEC at the early recovery phase of the storm.

20 November 2003 event in the Northern Hemisphere from the overall permanent receivers (900+). In Fig. 6 we present some of the snapshots where the storm effects on VTEC can be seen. We focus our attention on the European sector in the evening, due to the availability of two data types, and due to the very dramatic effects produced. From Fig. 6 one observes that under quiet conditions (snapshot 6a), VTEC values are lower at the nightside and at high latitudes. VTEC starts to increase around the auroral oval down to around $60^{\circ} \mathrm{N}$ at the initial phase of the storm (snapshot $6 \mathrm{~b}$ ). Around 18:0021:00 UT (snapshots c, d, e, and even f), one can notice the existence of a thin latitudinal belt between $55^{\circ}-45^{\circ} \mathrm{N}$, with lower VTEC values than those at the higher latitude, extending into the longitude sector $350^{\circ}-30^{\circ} \mathrm{E}$, this latitudinal belt being wider into the longitude sector $50^{\circ}-120^{\circ} \mathrm{E}$. In addition, an enhanced VTEC is clearly stated on the latitudinal belt between $45^{\circ}-30^{\circ} \mathrm{N}$ during the evening hours of 20 November, into the longitude sector $330^{\circ}-60^{\circ} \mathrm{E}$, approximately. This effect was expected to be observed from the ground ionosonde data; but the anomalous storm $E_{s}$ lay- ers hid the $F$-region evolution above Chilton and Pruhonice. However, from ionograms depicted in Fig. 2, one can see that the $F$-region electron density tends to depress strongly for Chilton. Although not shown here, Pruhonice had measurements at 5-min sampling, and some of the ionograms allow one to observe the $F$ region, indicating very low densities. Direct comparison between Figs. 2 to 6 supports the fact that in the European sector, in the evening, the storm caused a thin latitudinal belt $\left(55^{\circ}-45^{\circ} \mathrm{N}\right)$ with depressed electron densities in the $F$ region during the main phase of the storm (negative effect) and a positive effect in the latitudinal belt from $45^{\circ}$ to $30^{\circ} \mathrm{N}$. Moreover, we clearly observe from Fig. 6 that the auroral oval expands from $60^{\circ} \mathrm{N}$ at the initial phase of the storm (snapshot b) to latitudes as low as $45^{\circ} \mathrm{N}$ for the evening European sector at the main phase of the storm (snapshot e). 


\section{Summary and discussion}

Two periods of a suddenly enhanced solar activity in October and November 2003 resulted in two strong geomagnetic and ionospheric storms. The effects of both events were dangerous for satellite equipment and influenced many communication, navigation (GPS, GNNS) and technological systems. It is very interesting that the smallest storm produced a more dramatic effect on the Earth's ionosphere in the mid-latitude European sector. These rare types of effects are practically not predictable at this time.

Investigations of the mid-latitude sporadic $E$ layer carried out into the framework of COST 271 Action (http://www. cost271.rl.ac.uk/) have been briefly described by Bencze et al. (2004). In general, the frequency parameters of sporadic $E$ are considered as a quantity proportional to the mean iondensity of "patches" of increased ion density in the layer, and its temporal variation may indicate the mean periodicity of ion density changes. The "storm sporadic $E$ " is the most striking phenomenon in the ionospheric $E$ region. Usually it occurs at moderately high latitudes ranging from $78^{\circ}$ to $68^{\circ}$ and expands toward lower latitudes during disturbances (Rishbeth and Garriott, 1969). Electron density distribution at the heights of the storm sporadic $E$ layer has been studied by Thomas (1962) and is related to auroral oval phenomena. Ionospheric behavior, such as storm sporadic $E$, is attributed to intense, rapidly fluctuating and spatially limited "splashes" of precipitated particles.

During the November 2003 geomagnetic storm, the first effect we observed is the generation of "anomalous storm $E_{s}$ " layers, whose strength and blanketing intensity depend on latitude. The latter properties are larger at higher latitude. These anomalous layers appear down to mid-low latitude stations like El Arenosillo, but the occurrence was shorter compared to the higher latitude stations of Pruhonice and Chilton, due to the lower latitude of El Arenosillo. The height and shape of these "anomalous storm $E_{s}$ " layers are typical for layers formed by energetic particle precipitation. The existence of this particle layer does not permit one to follow the $F$ region response to the geomagnetic storm using ground ionosonde data in the higher latitude stations. However, the VTEC maps obtained from ground GPS receivers allow to follow the global response of the ionosphere, but we have no details on the vertical structure. Therefore, the use of both of these data types allows us to observe more than one distinct effect of the November storm over mid-latitude European sector.

The second effect we observe is the generation of two distinct latitudinal belts, in the European evening sector. During the main phase of the storm, a thin latitudinal belt $\left(55^{\circ}-\right.$ $45^{\circ} \mathrm{N}$ ) with depressed VTEC (negative effect) and an additional latitudinal belt $\left(45^{\circ}-30^{\circ} \mathrm{N}\right)$ with enhanced VTEC (positive effect) are observed. The latter effect, the so-called negative storm effect, can be explained by changes in composition caused by the storm, or it could be linked to the equatoward expansion of the main ionospheric trough caused by the storm. General circulation models shows realistic changes in neutral composition that account for negative storm effects (Fuller-Rowell et al., 1991). In addition, empirical models (Araujo-Pradere et al., 2004) show the dependence of the estimated variability of $f_{0} F_{2}$ on latitude, season and geomagnetic activity. They assessed dominant negative storm effects in the latitude range $80^{\circ}-40^{\circ} \mathrm{N}$ during winter and the intermediate seasons, and dominant positive storm effects in the latitude range $40^{\circ}-20^{\circ} \mathrm{N}$. Moreover, Burns et al. (1995) demonstrated that geomagnetic storms drive large enhancements of $\mathrm{O} / \mathrm{N}_{2}$ in a limited latitudinal region of the winter hemisphere in the evening sector. Such an effect would produce a depressed loss rate of electron density in the above limited region, leading to an enhancement of the electron density (Rishbeth and Barron, 1960). This fact of enhanced electron density in a limited latitudinal belt is just the one we observed from the VTEC maps and it can be explained by the facts described in Burns et al. (1995). As discussed by Burns et al. (1995) as well, such enhancements would be caused by large gravity wave, but only if its duration is lower than a few hours. Despite the enhancement of VTEC, we observe a long-lasting effect, persistent for more than $10 \mathrm{~h}$ after onset. Therefore, we believe that the changes in composition generated by the storm are the cause of the VTEC enhancements observed in the mid-latitude evening sector. Moreover, an additional belt of depressed VTEC has been noticed. Regarding the latter, the electric fields and particle populations which characterize the auroral region expand equatorward during geomagnetic storms, and their effects can be perceived at sub-auroral latitudes. Intense convection electric fields appear in the expanded auroral oval (Yeh et al., 1991) and are responsible for density depletion and ionospheric trough formation due to the effects of enhanced recombination (Schunk et al., 1976).

Acknowledgements. This paper is based on the results presented at the First European Space Weather Week, Noordwijk, December 2004, whose participation was funded by COST Action 724. The authors are grateful to El Arenosillo, Pruhonice and Chilton observatories, as far as to IGS for the data availability. The authors would like to thank the ACE SWEPAM instrument team and the ACE Science Center for providing the ACE data, and to the information from the Space Environment Center, Boulder, CO, National Oceanic and Atmospheric Administration (NOAA), US Dept. of Commerce.

This work has been partially supported by the Spanish project REN2003-08376-C02-02. The work of J. Boška and D. Burešová has been partially supported by the Grant of the Academy of Sciences of the Czech Republic S300120506. The work of last author has been partially supported by Spanish projects PETRI9507522.OP.01 and ESP2004-045682-C02-01.

Topical Editor M. Pinnock thanks I. Kutiev and another referee for their help in evaluating this paper. 


\section{References}

Araujo-Pradere, E. A., Fuller-Rowell, T. J., and Bilitza, D.: Ionospheric variability for quiet and perturbed conditions, Adv. Space Res., 34, 9, 1914-1921, 2004.

Bencze, P., Buresova, D., Lastovicka, J., and Marcz, F.: Behavior of the F1-region, and $E_{S}$ and spread- $F$ phenomena at European middle latitudes, particularly under geomagnetic conditions, Annals of Geophysics (Rome, Italy), 47, 2/3, 1131-1143, 2004.

Brown, G. M. and Wynne, R.: Solar daily disturbance variations in the lower ionosphere, Planet. Space Sci., 15, 1677-1686, 1967.

Buonsanto, M. J.: Ionospheric Storms - A review, Space Sci. Rev., 88, 563-601, 1999.

Burns, A. G., Killeen, T. L., and Carignan, G. R.: Large enhancements in the $\mathrm{O} / \mathrm{N} 2$ ratio in the evening sector of the winter hemisphere during geomagnetic storms, J. Geophys. Res., 100, 14 661-14671, 1995.

Danilov, A. D.: F2-region response to geomagnetic disturbances, J. Atmos. Sol.-Terr. Phys., 63, 441-449, 2001.

Davis, C. J., Wild, M. N., Lockwood, M., and Tulunay, Y. K.: Ionospheric and geomagnetic responses to changes in IMF Bz: a superposed epoch study, Ann. Geophys., 15, 217-230, 1997,

SRef-ID: 1432-0576/ag/1997-15-217.

Dungey, J.W.: Interplanetary magnetic field and the auroral zones, Phys. Rev. Lett., 6, 47-48, 1961.

Fuller-Rowell, T. J., Codrescu, M. V., Moffett, R. J., and Quegan, S.: Response of the thermosphere and ionosphere to geomagnetic storms, J. Geophys. Res., 99, 3893-3914, 1994.

Fuller-Rowell, T. J., Rees, D., Risbeth, H., Burns, A. G., Killeen, T. L., and Roble, R. G.: The composition change theory of F-region storms, J. Atmos. Terr. Phys., 53, 797-815, 1991.

Hernandez-Pajares, M., Juan, J. M., and Sanz, J.: New approaches in global ionospheric determination using ground GPS data, J. Atmos. Sol.-Terr. Phys., 61, 1237-1247, 1999.

Hernandez-Pajares, M., Juan, J. M., and Sanz, J.: Improving the real-time ionospheric determination from GPS sites at Very Long Distances over the Equator, J. Geophys. Res., 107, 1296-1305, 2002.

Hernandez-Pajares, M., Juan, J. M., Sanz, J., Farnworth, R., and Soley, S.: EGNOS Test Bed Ionospheric corrections under the October and November 2003 Storms, IEEE Transactions on Geoscience and Remote Sensing, 43, 10, 2283-2293, 2005.

Huang, X. and Reinisch, B. W.: Vertical electron density profiles from the Digisonde network, Adv. Space Res., 18, 6, 21-29, 1996.

King, G. A. M.: The night E-layer, in: "Ionospheric Sporadic E", edited by: Smith, E. K. and Matsushita, S., 219-231, Pergamon Press, Oxford, UK, 1962.

Lastovicka, J.: Monitoring and forecasting of ionospheric space weather - effects of geomagnetic storms, J. Atmos. Sol.-Terr. Phys., 64, 697-705, 2002.
Liu, J. Y., Lin, C. H., Tsai, H. F., and Liou, Y. A.: Ionospheric solar flare effects monitored by the ground-based GPS receivers: Theory and observation, J. Geophys. Res., 109, A01307, doi:10.1029/2003JA009931, 2004.

Mansilla, G. A.: Mid-latitude ionospheric effects of a great geomagnetic storm, J. Atmos. Sol.-Terr. Phys., 66, 1085-1091, 2004.

Ondoh, T. and Marubashi, K.: Overview of the science of the space environment, in: Science of space environment, edited by: Ondoh, T. and Marubashi, K., 1-27, Ohmsha, Ltd., Tokyo, Japan, 2001.

Prölss, G. W.: Physics of the Earths Space Environment, SpringerVerlag, Berlin Heidelberg, Germany, 2004.

Reinisch, B. W. and Huang, X.: Deducing topside profiles and total electron content form bottomside ionograms, Adv. Space Res., 27, 23-30, 2001.

Rishbeth, H. and Barron, D. W.: Equilibrium electron distributions in the ionospheric F2-layer, J. Atmos. Terr. Phys., 18, 234-252, 1960.

Rishbeth, H. and Garriott, O. K.: Introduction to ionospheric physics, Academic Press, New York and London, 1969.

Schunk, R. W., Banks, P. M., and Raitt, W. J.: Effects of electric fields and other processes upon the nighttime high-latitude $F$ layer, J. Geophys. Res., 81, 3271-3282, 1976.

Skoug, R. M., Gosling, J. T., Steinberg, J. T., McComas, D. J., Smith, C. W., Ness, N. F., Hu, Q., and Burlaga, F. L.: Extremely high speed solar wind: 29-30 October 2003, J. Geophys. Res., 109, A09102, doi:10.1029/2004JA010494, 2004.

Thomas, L.: The distribution of dense $E_{S}$ ionisation at high latitudes J. Atmos. Terr. Phys., 24, 643-658, 1962.

Thomson, N. R., Rodger, C. J., and Dowden, R. L.: Ionosphere gives size of greatest solar flare, Geophys. Res. Lett., 31, L06803, doi:10.1029/2003GL019345, 2004.

U.R.S.I.: Handbook of ionogram interpretation and reduction, edited by: Piggott, W. R. and Rawer, K., WDC A, National Academy of Sciences, Washington, D. C., USA, 1978.

U.R.S.I.: Manual of ionogram scaling, Revised Edition, edited by: Wakai, N., Ohyama, H., and Koizumi, T., Radio Research Laboratory, Japan, 1986.

Woods, T. N., Eparvier, F. G., Fontenla, J., Harder, J., Kopp, G., McClintock, W. E., Rottman, G., Smiley, B., and Snow, M.: Solar irradiance variability during the October 2003 solar storm period, Geophys. Res. Lett., 31, L10802, doi:10.1029/2004GL019571, 2004.

Yeh, H.-C., Foster, J. C., Rich, F. J., and Swieder, W.: Storm-time field penetration observed at mid-latitude, J. Geophys. Res., 96, 5707-5721, 1991.

Yin, P., Mitchell, C. N., Spencer, P. S. J., and Foster, J. C.: Ionospheric electron concentration imaging using GPS over the USA during the storm of July 2000, Geophys. Res. Lett., 31(L12806), doi:10.1029/2004GL019899, 2004. 